\title{
Transcriptional co-regulation of neuronal migration and laminar identity in the neocortex
}

\author{
Kenneth Y. Kwan ${ }^{1}$, Nenad Šestan ${ }^{1, *}$ and E. S. Anton ${ }^{2, *}$
}

\begin{abstract}
Summary
The cerebral neocortex is segregated into six horizontal layers, each containing unique populations of molecularly and functionally distinct excitatory projection (pyramidal) neurons and inhibitory interneurons. Development of the neocortex requires the orchestrated execution of a series of crucial processes, including the migration of young neurons into appropriate positions within the nascent neocortex, and the acquisition of layer-specific neuronal identities and axonal projections. Here, we discuss emerging evidence supporting the notion that the migration and final laminar positioning of cortical neurons are also co-regulated by cell type- and layerspecific transcription factors that play concomitant roles in determining the molecular identity and axonal connectivity of these neurons. These transcriptional programs thus provide direct links between the mechanisms controlling the laminar position and identity of cortical neurons.
\end{abstract}

Key words: Neuronal specification, Neuronal migration, Neuronal identity, Axon pathfinding, Pyramidal neuron, Neuronal circuits, Cerebral cortex

\section{Introduction}

The cerebral cortex, an extensive sheet of neural tissue at the most superficial part of the cerebral hemispheres, is involved in a variety of higher cognitive, emotional, sensory and motor functions. The emergence of a six-layered neocortex, the phylogenetically most recent part of the cerebral cortex, and its extensive projections to subcortical regions are key features of mammalian evolution. The ability of the neocortex to mediate complex cognitive and motor tasks depends on the accurate execution of molecular processes that control the identity and positioning of neurons and the formation of their precise synaptic connections during development. The incorrect formation of neocortical organization and circuitry might lead to cognitive impairments and increased susceptibility to major psychiatric and neurological disorders (Valiente and Marín, 2010; Liu, 2011; Manzini and Walsh, 2011; Rubenstein, 2011).

The neocortex is composed of six horizontal layers (L1-L6; see Glossary, Box 1) that are cytoarchitectonically and functionally distinct. Each layer contains a unique subset of neurons (Fig. 1), including glutamatergic excitatory projection (pyramidal) neurons (see Glossary, Box 1) and GABAergic inhibitory interneurons (see Glossary, Box 1) (Jones, 1986; DeFelipe and Farinas, 1992). Furthermore, the projection neurons of L2-L6 exhibit marked layer-

\footnotetext{
${ }^{1}$ Department of Neurobiology and Kavli Institute for Neuroscience, Yale University School of Medicine, New Haven, CT 06510, USA. ${ }^{2}$ UNC Neuroscience Center and the Department of Cell and Molecular Physiology, University of North Carolina School of Medicine, Chapel Hill, NC 27599, USA.
}

*Authors for correspondence (anton@med.unc.edu; nenad.sestan@yale.edu) and subtype-specific differences in their molecular expression and axon projections (DeFelipe and Farinas, 1992; O'Leary and Koester, 1993; Molyneaux et al., 2007). For example, corticofugal axons targeting subcortical structures arise solely from deep-layer (L5 and L6) and subplate (SP; see Glossary, Box 1) neurons, whereas upper-layer (L2-L4) neurons project within the cortex, either intra-hemispherically or contralaterally, mostly via the corpus callosum (see Glossary, Box 1). In addition to projection neurons, interneurons of distinct lineages and morphological, neurochemical and electrophysiological subtypes also populate the neocortex with certain layer preferences, thus contributing to layer differences in local circuits (Markram et al., 2004; Miyoshi et al., 2007; Miyoshi and Fishell, 2011). Although this review is focused on the layered horizontal organization of the neocortex, it should be noted that the neocortex is also tangentially organized into cytoarchitectonically and functionally distinct areas (Rakic, 1988; Rash and Grove, 2006; O'Leary and Sahara, 2008).

The emergence of laminar-dependent patterns of functional neocortical connectivity depends on two crucial early developmental processes: (1) the migration of neurons to their final position within the nascent neocortex; and (2) the acquisition of distinct neuronal identities and connections. The molecular mechanisms that regulate these developmental processes are being unraveled and remain a highly active area of research (Marín and Rubenstein, 2003; Rash and Grove, 2006; Wonders and Anderson, 2006; Molyneaux et al., 2007; Leone et al., 2008; Batista-Brito and Fishell, 2009). A number of transcription factors have been shown to play important roles in many aspects of neocortical development, including early patterning, neurogenesis and arealization (Monuki and Walsh, 2001; Hevner et al., 2006; Mallamaci and Stoykova, 2006; Guillemot, 2007; Hébert and Fishell, 2008; O'Leary and Sahara, 2008). Here, we review emerging evidence that points to the concomitant control of neuronal positioning and acquisition of laminar and projectional identity by cell type- and layer-specific transcriptional programs in the mammalian neocortex. We also discuss the potential downstream pathways mediating the roles of these transcriptional programs, and how they might co-regulate distinct processes of neocortical development.

\section{Neuronal generation and migration in the cerebral cortex \\ The generation of neocortical projection neurons}

Cortical projection neurons are born in the dorsal germinal zones of the telencephalon, the ventricular and subventricular zones (VZ and SVZ; see Glossary, Box 1) (Angevine and Sidman, 1961). They then undergo radial migration through the intermediate zone (IZ; see Glossary, Box 1), guided by radial glial cells (RGCs; see Glossary, Box 1), to reach their final destination in the mantle layers (Fig. 2) (Rakic, 1988). Starting at around embryonic day (E) 10.5 in mouse, the earliest generated cortical neurons form the 


\section{Box 1. Glossary}

Cajal-Retzius cells. Located in the MZ, these neurons are some of the first to mature in the neocortex and are the main source of reelin, a secreted protein important for normal cortical lamination.

Corpus callosum. A large collection of intracortical axonal projections connecting the left and right cerebral hemispheres and that arises mostly from projection neurons of the upper layers.

Cortical plate (CP). A cell-dense structure that contains postmigratory projection neurons. It is formed as projection neurons split the PP and is expanded as L2-L6 neurons migrate into the CP in a sequential manner. During later periods of development, CP may refer to the cell-dense upper layers.

Ganglionic eminences. Transient structures in the embryonic ventral forebrain that serve as the source of striatal neurons and cortical interneurons. The ganglionic eminences are subdivided based on their location (caudal, CGE; lateral, LGE; medial, MGE) and each eminence preferentially gives rise to certain subtypes of cortical and other forebrain interneurons

Intermediate zone (IZ). A relatively cell sparse zone through which projection neurons migrate radially to reach the $C P$. The $I Z$ also contains tangentially migrating interneurons and afferent and efferent axons that form the white matter of the postnatal neocortex.

Interneurons. Constituting $20 \%$ of cortical neurons, these inhibitory (GABAergic) interneurons mostly project axons within a local circuit. They are highly diverse in morphology, neurochemical marker expression, electrophysiological properties and axonal targeting of projection neuron compartments.

Layers $\mathbf{2}$ and $\mathbf{3}$ (L2/L3). Contain projection neurons that project intracortically and contribute significantly to the corpus callosum. L2 and L3 together are termed the supragranular layers (whereas L2-L4 are considered to be the upper layers of the neocortex).

Layer 4 (L4). Contains pyramidal and spiny stellate (granule) neurons and is the main recipient layer of thalamocortical axons that relay sensory information. L4 is also termed the granule layer of the neocortex

Layer 5 (L5). Contains large projection neurons that form the vast majority of subcerebral axons, including those of the corticobulbar, corticospinal, corticotectal and corticopontine tracts. The collateral axons of $L 5$ neurons also innervate the striatum and thalamus.

Layer 6 (L6). Contains projection neurons that contribute significantly to the corticothalamic tract. Together, L5 and L6 are termed the deep or subgranular layers of the neocortex.

Marginal zone (MZ)/Layer $\mathbf{1}$ (L1). The MZ (which becomes L1 in the postnatal cortex), the most superficial cortical layer, is split from the SP during segregation of the PP. Developmentally, it serves as a corridor for the tangential migration of interneurons and it contains Cajal-Retzius neurons.

Preplate (PP). A transient cell-dense structure, which was formerly termed the early $\mathrm{MZ}$ or primordial plexiform layer, that contains some of the earliest-born cortical neurons. It is split by incoming CP neurons into the superficial MZ and deep SP.

Projection (pyramidal) neurons. Representing 80\% of all cortical neurons, these are excitatory (glutamatergic) projection neurons that exhibit a pyramid-shaped soma, an apical dendrite directed towards the pial surface, and multiple basal dendrites. The dendrites are decorated with spines, which are membranous protrusions that receive synaptic inputs. Projection neurons extend a single axon, which can reach long distances, either intracortically or subcortically.

Radial glial cells (RGCs). RGCs serve as both the progenitor cells for cortical projection neurons and as a radial scaffold that guides migrating neurons towards the CP. With an elongated morphology that spans the cortical wall, they extend a long basal process attached to the pial surface and a shorter apical process to the ventricle. Radial glia-like cells lacking an apical process can be found in the mouse SVZ and are called the outer RGCs (oRGCs).

Spiny stellate neurons. These cells, mainly residing in L4 of primary sensory areas, are locally projecting glutamatergic neurons that play a crucial role in the receipt of sensory information from the thalamus. They acquire their stellate shape via morphologic remodeling, which is likely to be activity dependent, from pyramidal neurons during the early postnatal stages.

Subplate (SP). Transient developmental zone formed immediately below the forming $\mathrm{CP}$, when the PP is split by incoming CP neurons. Containing early-generated neurons, the SP is thought to be important for the migration of later-born CP neurons and the guidance and targeting of cortical afferent and efferent axons. Many interneurons also migrate tangentially along the SP prior to entering the CP.

Subventricular zone (SVZ). The SVZ is the secondary germinal zone of the neocortex and is thought to contribute significantly to upper layer neurons. The intermediate progenitor cells (IPC) of the SVZ are derived from VZ progenitor cells. In the postnatal neocortex, the subependymal zone (SEZ) is sometimes referred to as the SVZ. Although distinct from the embryonic SVZ, the SEZ does contain neural progenitors and serves as one of a small number of sites of postnatal neurogenesis

Ventricular zone (VZ). The VZ is the primary germinal zone of the dorsal telencephalon and contains progenitor cells that give rise to projection neurons during neurogenesis, astrocytes during gliogenesis, and ependymal cells that line the ventricles of the postnatal cerebral hemispheres. preplate (PP; see Glossary, Box 1), a band of cells positioned at the superficial part of the cortical wall (The Boulder Committee, 1970; Marin-Padilla, 1971; Marin-Padilla, 1978; De Carlos and O'Leary, 1992). The first cortical projection neurons, born at $\sim \mathrm{E} 11.5$ in mouse, migrate to settle as a layer within the PP, thus forming the nascent cortical plate (CP; see Glossary, Box 1), which subsequently develops into L2-L6 of the postnatal neocortex (Marin-Padilla, 1978). Incoming CP neurons split the PP into the superficial marginal zone (MZ; see Glossary, Box 1), which develops into L1 of the postnatal cortex, and the deeper subplate (SP), which is situated below L6 (Molliver et al., 1973). The neurons of the MZ and the SP, the first to achieve morphological maturity and form synapses, are thought to play crucial roles in the migration and synaptogenesis of CP neurons, as well as in the formation of proper cortical efferent and afferent projections (Molliver et al., 1973; Rakic, 1976; Kostovic and Rakic, 1980; Kostovic and Rakic, 1990; Allendoerfer and Shatz, 1994; Herrmann et al., 1994).
As neurogenesis progresses, diverse subtypes of projection neurons are generated sequentially and their migration into the mantle layers occurs in an inside-first, outside-last manner (Fig. 2). During this sequential generation of projection neurons, the neurons that will eventually occupy the deepest layers of the future sixlayered neocortex are generated first, followed by those that will ultimately settle in more superficial layers (Angevine and Sidman, 1961; Rakic, 1974; Caviness, 1982; Frantz and McConnell, 1996). The radial migration of neurons into the neocortex is also ordered. Upon entering the $\mathrm{CP}$, newly generated neurons migrate past older, post-migratory neurons to reach the most superficial portion of the $\mathrm{CP}$, where they arrest their migration and undergo molecular and morphological differentiation into neuronal subtypes appropriate to their layer location (D'Arcangelo and Curran, 1998; Lambert de Rouvroit and Goffinet, 1998; Anton et al., 1999; Yokota et al., 2007a). Therefore, the birthdate of cortical projection neurons is intimately associated with laminar identity and, hence, axonal connectivity and eventual physiological function. 


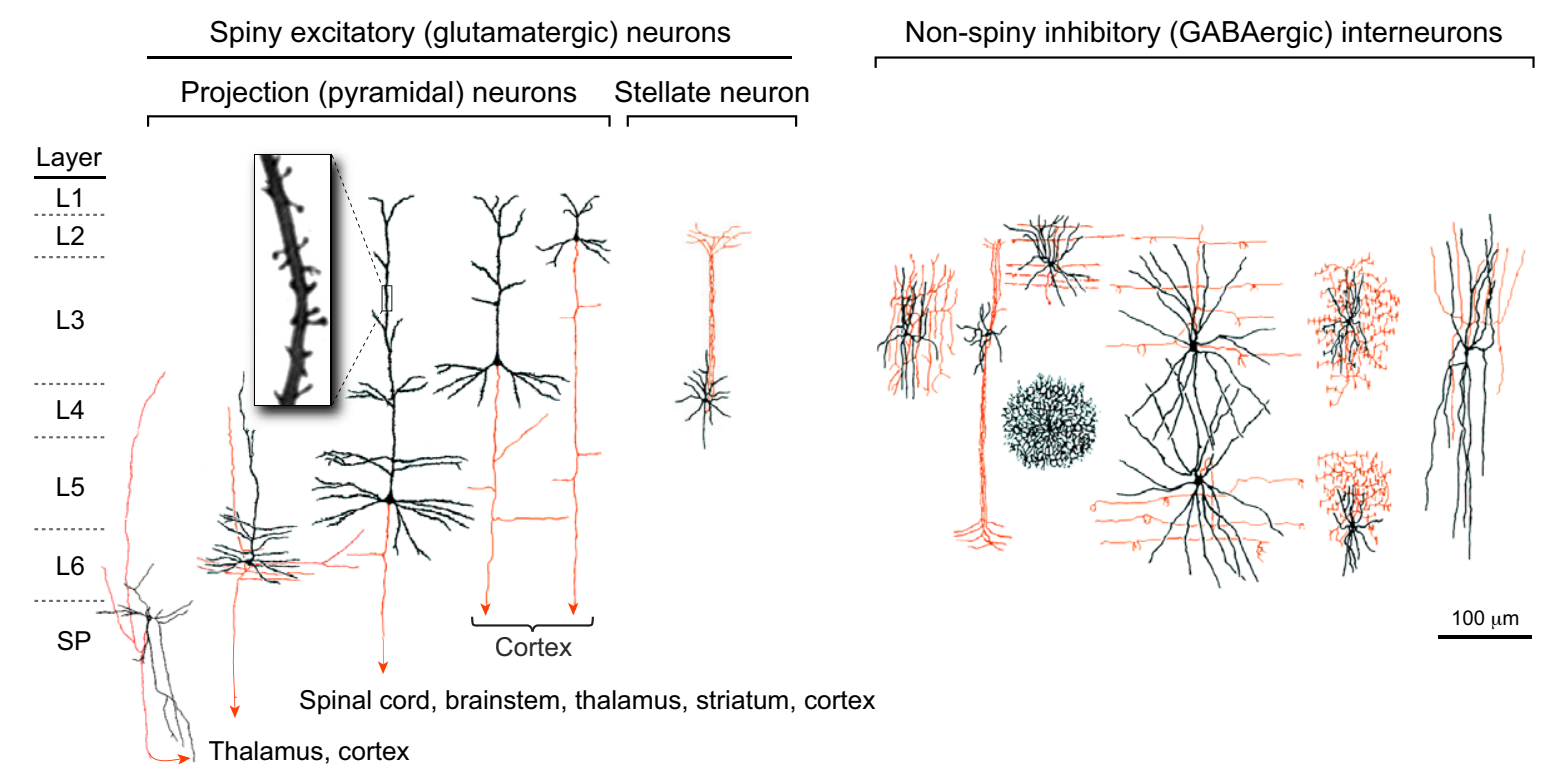

Fig. 1. Major neuronal cell types of the adult cerebral cortex. Cortical neurons (shown here for primates) are categorized into two major classes: spiny excitatory (glutamatergic) neurons (left panel) and non-spiny inhibitory (GABAergic) interneurons (right panel). The former, the dendrites of which are decorated by numerous post-synaptic membranous protrusions termed spines (see inset), include the projection (pyramidal) neurons, the principal cells of the neocortex, and stellate neurons (see Glossary, Box 1), which are mostly found in L4 of primary sensory areas. Projection neurons display marked layer- and subtype-specific differences in the morphology of their dendrites (black) and in the targets of their axonal projections (red); neurons within the deep layers (L5 and L6) and the subplate (SP) project axons that target cortex and subcortical structures, including striatum, thalamus, brainstem and spinal cord, whereas upper-layer (L2-L4) neurons project axons within the cortex. The non-spiny interneurons, which are highly diverse in morphology, neurochemistry and electrophysiology, project axons within a local circuit. Subtypes of interneurons also display laminar preferences, thereby contributing to layer differences in cortical circuitry. Adapted from Jones (Jones, 1986).

\section{Migration of neocortical projection neurons}

The radial migration of projection neurons towards the $\mathrm{CP}$ does not follow a straight-forward route and includes phases of temporary migratory arrest and retrograde migration prior to entering the CP (Noctor et al., 2004a). During these phases, migrating neurons transition between bipolar and multipolar morphologies (Tabata and Nakajima, 2003; Kriegstein and Noctor, 2004; LoTurco and Bai, 2006). The molecular pathways controlling distinct steps of neuronal migration and morphological transformation therein have been the focus of recent studies and several review articles (Kriegstein and Noctor, 2004; Hand et al., 2005; Ge et al., 2006; LoTurco and Bai, 2006; Kawauchi and Hoshino, 2008; Kawauchi et al., 2010; Valiente and Marín, 2010; Alfano et al., 2011; Pacary et al., 2011; Westerlund et al., 2011). It is interesting to note, however, that mutations affecting genes that control different aspects of neuronal migration can lead to dramatic brain malformations, such as lissencephaly, and periventricular and cortical band heterotopias, highlighting the importance of the migration process. These include mutations in genes encoding cytoskeletal regulators, such as doublecortin (DCX), filamin A, alpha (FLNA), platelet-activating factor acetylhydrolase $1 \mathrm{~b}$, regulatory subunit 1 (PAFAH1B1, formerly LIS1), and in genes encoding tubulin subunits (TUBA1A, TUBB2B and TUBB3) (Liu, 2011; Manzini and Walsh, 2011). Interestingly, loss of function of the mouse orthologs of FLNA or PAFAH1B1 leads to accumulation of multipolar cells in the VZ and SVZ (Nagano et al., 2004; Tsai et al., 2005) and, by contrast, DCX knockdown in rats leads to accumulation of multipolar cells in the IZ (Bai et al., 2003). Furthermore, increases in FLNA activity enhance the multipolarto-bipolar transition, whereas overexpression of DCX increases the number of bipolar cells in the IZ (LoTurco and Bai, 2006), highlighting the distinct requirements for efficient morphological transformations during radial migration. These changes in morphology are thought to facilitate the initial axonal protrusion of these neurons (Noctor et al., 2004b; Tabata et al., 2009), thereby contributing to the formation of projections, and might also help trigger neuronal differentiation programs. In addition, recent studies have shown that the proper detachment of migrating neurons from their radial glial guides in the upper CP is a critical step in migration termination. This process might require the coordination of a multitude of mechanisms, including radial glia-based anti-adhesion signals, such as SPARC-like 1 (SPARCL1 or SC1), changes in neuronal response to ambient glutamate and GABA (Gongidi et al., 2004; Bortone and Polleux, 2009), and the induction of neuronal cytoskeletal modulators, such as NCK-associated protein 1 (NCKAP1 or NAP1), which helps to convert the neuronal cytoskeleton from one that is primed to facilitate movement to one that promotes axon and dendrite outgrowth (Yokota et al., 2007b).

These mechanisms of neuronal migration mainly control the fundamental aspects of glial-guided neuronal motility, including cell-cell interactions, cytoskeletal dynamics, leading process extension, somal translocation and migration termination. The determination of ultimate laminar position, however, depends on one of the final steps of neuronal migration: moving past older neurons. Crucial findings about this late event in cortical neuronal migration have come from studies of the cortex of Reeler mutant mice, in which newborn projection neurons fail to migrate past older neurons, arresting just below (Caviness, 1982; Rice and Curran, 2001; Tissir and Goffinet, 2003). As a result, the partitioning of the PP by CP neurons fails and the lamination of L2- 


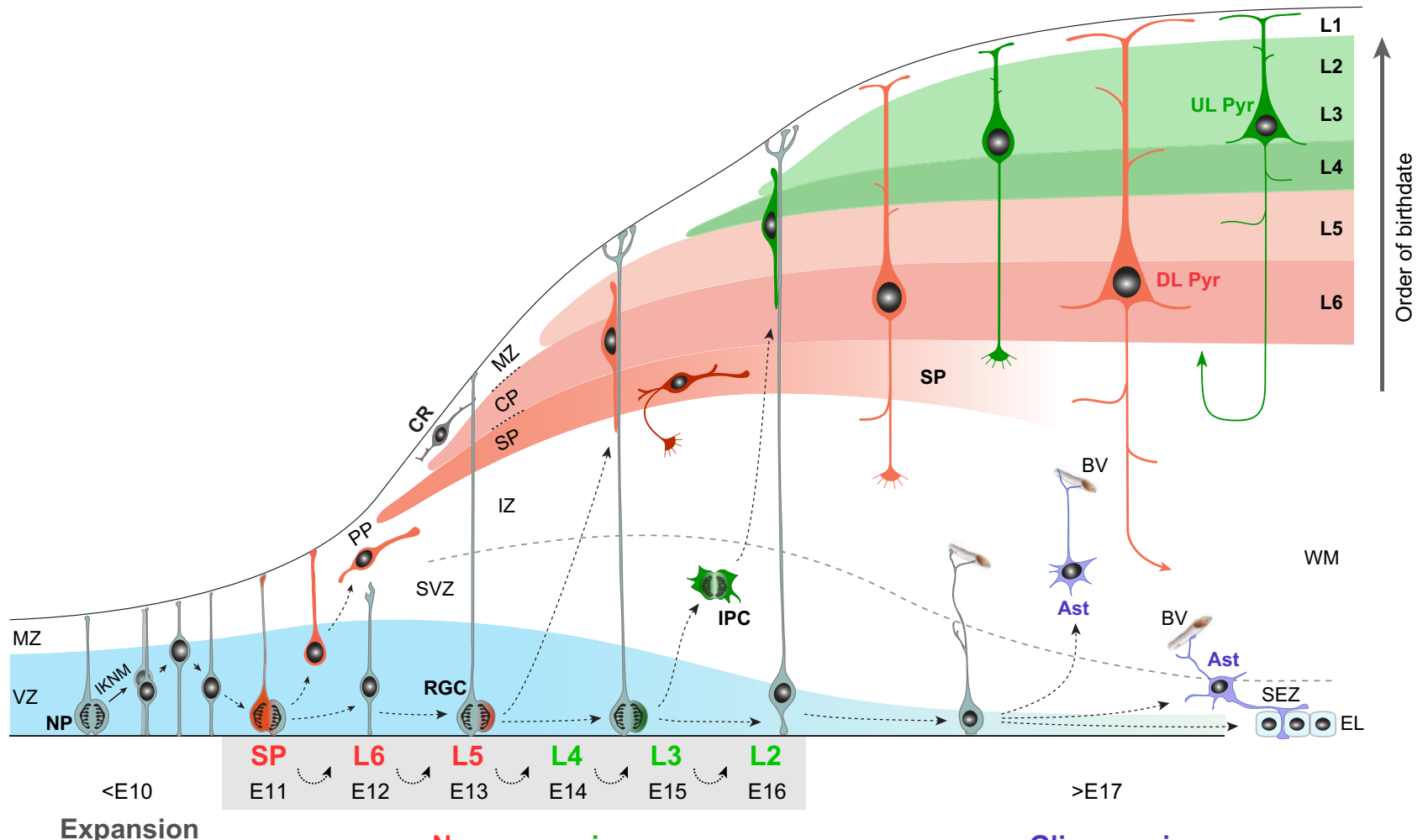

Expansion of NP pool

Neurogenesis

Gliogenesis

Fig. 2. Schematic of projection neuron generation and migration in the mouse neocortex. Prior to the onset of neurogenesis, neural progenitors (NPs) in the ventricular zone (VZ; blue) of the developing neocortex divide symmetrically to expand the progenitor pool, undergoing interkinetic nuclear migration (IKNM) as they progress through the cell cycle. Starting at E11.5, NPs assume radial glial morphology and begin dividing asymmetrically to generate neurons, which migrate from the germinal zones guided by radial glia cells (RGC) to reach the mantle layers. The first projection neurons settle within the preplate (PP) to form the nascent cortical plate (CP), which will subsequently become layers (L) 2 to 6 of the neocortex. Additional incoming CP neurons then split the PP into the marginal zone (MZ) and the subplate (SP). As neurogenesis progresses, diverse subtypes of projection neurons are generated sequentially through successive asymmetric divisions of NPs. Thus, neurons destined for the SP are generated first, followed by those destined for the deep layers (L6 and L5; red), and finally, those destined for the upper layers (L4, L3 and L2; green). The migration of newborn neurons into the CP occurs in an inside-first, outside-last manner; early-born neurons form the deep layers, whereas later-born neurons migrate past older neurons to form more superficial layers. Therefore, the cortical layers are sequentially generated in an 'inside-out' fashion. Some daughter cells of NPs become intermediate progenitor cells (IPCs), migrating away from the VZ and undergoing symmetric neurogenic divisions in the SVZ. This mode of neurogenesis contributes significantly to upper layer neurons. At the end of neurogenesis at E17.5, the radial scaffold is dismantled and NPs become gliogeneic, generating cortical and subependymal zone (SEZ) astrocytes (Ast) and giving rise to a layer of ependymal cells (EL). The tangential migration and laminar positioning of interneurons are not illustrated. BV, blood vessel; CR, Cajal-Retzius neuron; DL Pyr, deep-layer pyramidal neuron; IZ, intermediate zone; UL Pyr, upper-layer pyramidal neuron, WM, white matter.

$\mathrm{SP}$ is inverted (Fig. 3A,B). Reeler mice lack reelin (RELN), an extracellular matrix glycoprotein that is secreted mainly by MZ Cajal-Retzius cells (see Glossary, Box 1) over the period of cortical neuron migration. Research since the original discovery of the Reln gene has uncovered many components of its signaling pathway. The definitive role of RELN in neuronal migration and layer formation, however, has remained elusive. Furthermore, although the requirement for the Reln signaling pathway in this late step of migration seems to be shared amongst all projection neurons, whether neurons of different subtypes or layers have additional distinct molecular requirements for positioning in their appropriate laminar destination remains an unresolved question.

\section{Generation and migration of neocortical inhibitory interneurons}

Unlike the projection neurons, the inhibitory interneurons of the cerebral cortex are generated from distinct progenitor cells in the germinal zones of the ventral forebrain, mainly within the medial and caudal ganglionic eminences (MGE and CGE; see Glossary, Box 1) (Anderson et al., 1997; Nadarajah and Parnavelas, 2002; Marín and Rubenstein, 2003; Xu et al., 2004; Wonders and Anderson, 2006). They then undergo tangential migration into the dorsal forebrain, primarily taking routes both above and below the $\mathrm{CP}$. Recently, it has been shown that chemokine signaling involving C-X-C motif ligand 12 (CXCL12) and its receptors CXCR4 and CXCR7 regulates the tangential migratory stream of interneurons (Sessa et al., 2010; Sánchez-Alcañiz et al., 2011; Wang et al., 2011). Although it has been suggested that some interneurons are derived from dorsal progenitors in the human fetal neocortex (Letinic et al., 2002; Yu and Zecevic, 2011), certain human interneuron subtypes are probably generated in the ventral telencephalon and enter the cortex via tangential migration (Fertuzinhos et al., 2009). Upon arrival in the neocortex, interneurons migrate radially to enter the $\mathrm{CP}$ (Nadarajah and Parnavelas, 2002; Ang et al., 2003; Yokota et al., 2007a) and segregate into their layer destinations based on their molecular 
A

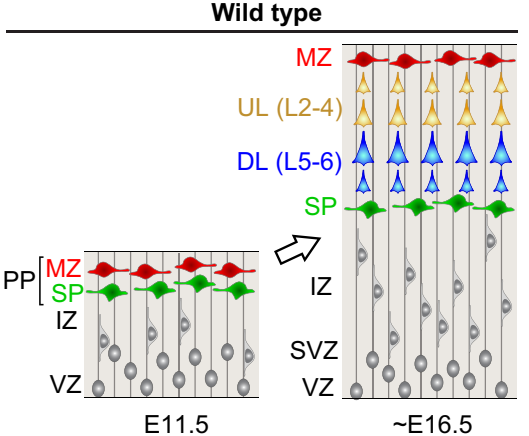

B

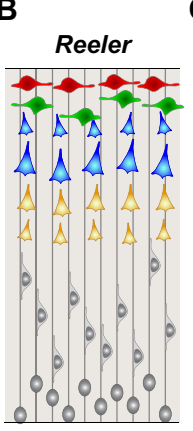

C

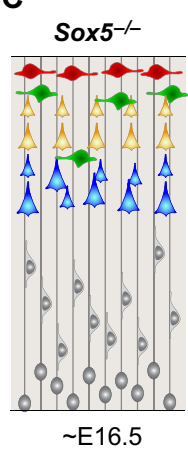

D

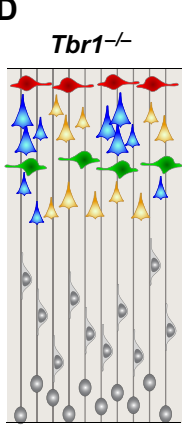

E
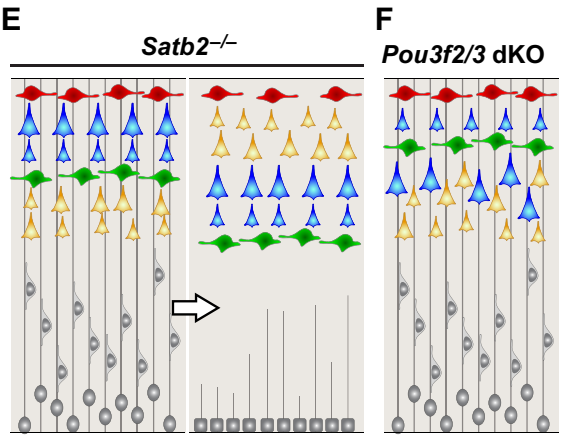

$\sim \mathrm{E} 16.5$

$\sim \mathrm{P} 7$

$\sim \mathrm{E} 16.5$

Fig. 3. Summary of neocortical neuronal migration and positioning defects in knockout mice. (A) Migration and laminar positioning in wild-type mouse. (B) In the cortex of Reeler mutants, preplate (PP) splitting is defective and lamination of the subplate (SP) and the entire cortical plate (CP) (L6-L2) is inverted. (C) In the Sox5-deficient cortex, the PP also fails to segregate but only the deep layers (DL) are inverted. The upper layers (UL) are formed without overt defect. (D) In the Tbr1-deficient cortex, the PP is partially split but the SP is mis-positioned to the middle of the CP. Deep-layer neurons form abnormal clusters and the majority of upper-layer neurons fail to migrate past the ectopic SP. (E) In the Satb2-deficient cortex, the migration of late-born neurons is delayed. This defect, however, is corrected within the first postnatal week. (F) In the Pou3f2/3 double knockout (dKO) neocortex, the PP is split and SP and L6 are formed without abnormality. The migration of L5-L2 projection neurons, however, is stalled below the SP. IZ, intermediate zone; MZ, marginal zone; P, postnatal day; SVZ, subventricular zone; VZ, ventricular zone.

subtype, origin and birthdate during early postnatal development (Miyoshi et al., 2010; Miyoshi and Fishell, 2011). The molecular basis of their laminar and areal preference, and integration with their radially derived counterparts, remains to be fully explored. Recent evidence suggests, however, that a laminar-specific transcription factor functioning in projection neurons might play a non-cell-autonomous role in the positioning and distribution of tangentially derived interneurons (Lodato et al., 2011).

\section{Neuronal birthdate, migration and laminar identity are linked}

Because of the sequential nature of cortical projection neuron generation from single progenitor lineages, neuronal birthdate is directly linked to laminar position, molecular identity and axonal connectivity and, hence, eventual physiological function. Therefore, it is theoretically possible for these aspects of neuronal position and identity to be wholly specified at the time of neuronal birth. Studies of the Reeler mutant have provided crucial insights into the relationship between neuronal birthdate, position and identity. Within the inverted neocortex of Reeler mutants, projection neurons maintain the molecular and projection identity typical of their birthdate, rather than that of their ectopic laminar position, suggesting that the specification of distinct neuronal cell types is intimately linked to their birthdate (Steindler and Colwell, 1976; Caviness, 1982; Rice and Curran, 2001; Tissir and Goffinet, 2003). Recent evidence suggests, however, that identity is not wholly specified at the time of neuronal birth and that post-mitotic determinants, mostly transcription factors, also play a role in regulating lamina- and area-dependent molecular identity and projections (Hevner et al., 2001; Alcamo et al., 2008; Lai et al., 2008; Britanova et al., 2008; Joshi et al., 2008; Kwan et al., 2008; Bedogni et al., 2010; Han et al., 2011; McKenna et al., 2011). Interestingly, many of these post-mitotic transcriptional programs also control the layer positioning of neurons by participating in the late stages of neuronal migration (Hevner et al., 2001; Britanova et al., 2008; Kwan et al., 2008). These findings together suggested that distinct processes of projection neuron development might be regulated by shared molecular mechanisms, a possibility that had not been specifically explored. Examples of similar co-regulation can be found in cortical interneurons, in which neuronal migration, fate specification, and differentiation are known to be mediated by shared transcriptional programs involving members of the distalless homeobox (DLX) and NK2 homeobox (NKX) families (Anderson et al., 1997; Cobos et al., 2007; Butt et al., 2008; Du et al., 2008; Nóbrega-Pereira et al., 2008).

Below, we discuss recent evidence supporting the view that, in projection neurons, the final steps of migration and the emergence of laminar identity are transcriptionally co-regulated, focusing on the layer-specific programs that concomitantly control the positioning of neurons and their cell type-specific properties. The potential downstream mediators of these transcriptional programs and how they might function in distinct aspects of projection neuron development are also discussed.

\section{Transcriptional programs of neuronal positioning and identity}

\section{Genetic programs regulating early-born neurons}

Early-born neurons occupy the deep layers of the neocortex and project mainly subcortical axons. Several gene expression studies have identified a number of genes, including those encoding transcription factors, that are selectively expressed or enriched in particular layers or subtypes of cortical projection neurons, (Arlotta et al., 2005; Chen et al., 2005b; Sugino et al., 2006; Heiman et al., 2008). Among these is sex determining region Y-box 5 (Sox5), which encodes a member of the large family of SOX transcription factors. SOX5 is specifically expressed in post-mitotic SP and L6 projection neurons, and in a subset of L5 projection neurons, from E14.5 to the first postnatal week (Fig. 4A), at which point some upper layer neurons also express SOX5 at low levels (Kwan et al., 2008; Lai et al., 2008). Moreover, analyses of mice lacking Sox5 showed that Sox 5 regulates the migration, molecular differentiation, and axonal projections of deep-layer neurons (Kwan et al., 2008; Lai et al., 2008). Throughout embryonic development, SOX5 is absent from progenitor cells of the cortical VZ and SVZ and newly born migrating neurons of the IZ, indicating that SOX5 functions by controlling post-mitotic, late-stage migratory events. Consistent with its expression pattern, SOX5 is required for the expression of connective tissue growth factor (Ctgf) in SP neurons and refines the 

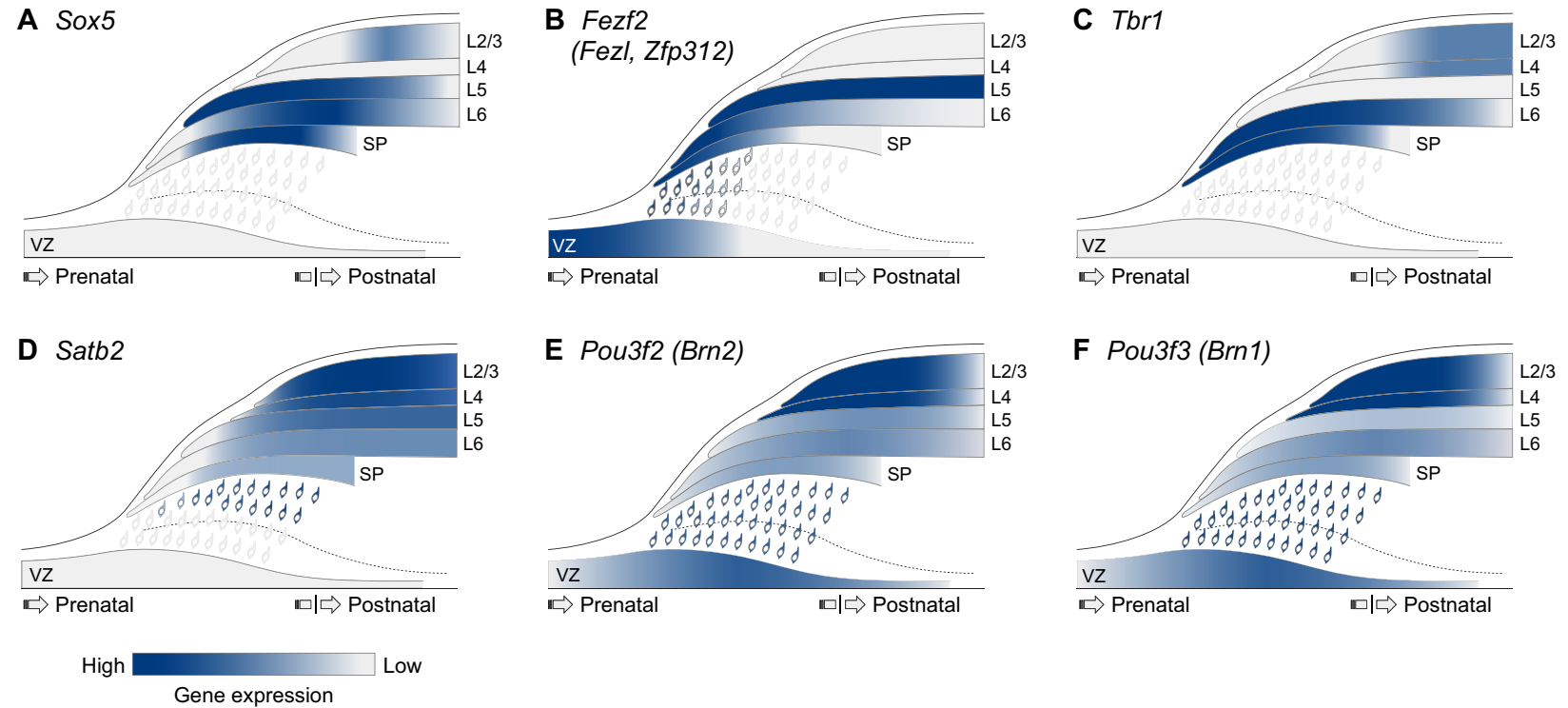

Gene expression

Fig. 4. Summary of spatiotemporal expression of transcription factors co-regulating neuronal migration and identity in the mouse neocortex. (A) Sox5 is specifically expressed in post-mitotic neurons and is absent from ventricular zone (VZ) and subventricular zone (SVZ) progenitors. From embryonic development until the perinatal period, its expression is specific to the deep layers, being strongly present in L6 and subplate (SP) neurons and in some L5 neurons. After the first postnatal week, some upper layer neurons also express Sox5. (B) Fezf2 is highly expressed in early VZ progenitors and their subcortically projecting deep-layer neuron progenies, but is absent from the upper-layer neurons and the late progenitors from which they are derived. In late embryonic development, Fezf2 is post-mitotically downregulated in L6 neurons, thereby giving rise to its L5-enriched postnatal pattern. (C) Tbr1 is specifically expressed in post-mitotic corticothalamic neurons of L6 and the SP, from embryonic development through to the first postnatal week. Thereafter, some upper layer neurons also turn on Tbr1 expression. (D) Satb2 is highly expressed in post-mitotic corticocortical L2-L5 neurons, beginning as these neurons migrate through the intermediate zone (IZ) and persisting postnatally. It is absent from subcortical projection neurons. (E,F) Pou3f2 and Pou3f3 are expressed in late progenitors and in their L2-L5 neuron progenies. Pou3f2 and Pou3f3 expression persists in these neurons, from their generation and migration, through their post-migratory differentiation and beyond.

layer-specific molecular identity of deep-layer neurons by downregulating the genes encoding two transcription factors, fez family zinc finger 2 (Fezf2, formerly Fezl or Zfp312) and B cell leukemia/lymphoma 11B (Bcll1b, formerly Ctip2), that are specifically enriched in L5 (Fig. 4B) and which become aberrantly overexpressed in L6 and SP neurons in Sox5-deficient mice (Kwan et al., 2008; Lai et al., 2008). Furthermore, SOX5 is critical for the development of layer-dependent corticofugal connectivities; in Sox5-deficient mice, corticothalamic axons arising from SP and L6 neurons are misrouted to the hypothalamus. Paradoxically, despite exhibiting an upregulation of $F e z f 2$ and $B c l 11 b$, which are each required for L5 subcortical axon development (Arlotta et al., 2005; Chen et al., 2005a; Chen et al., 2005b; Molyneaux et al., 2005), Sox5-deficient mice lack projections to the pons and spinal cord (corticospinal tract) (Kwan et al., 2008).

Concomitant with its role in regulating layer-specific patterns of molecular identity and projections, SOX5 specifically controls the laminar position of early-born projection neurons destined for the SP and deep cortical layers. In Sox5-deficient mice, many SP neurons do not separate from the MZ during PP splitting (Fig. 3C), and they become ectopically positioned at the upper edge of L2 (Kwan et al., 2008; Lai et al., 2008). Furthermore, Sox 5 is required for the migration of deep-layer neurons past earlier-born neurons to settle more superficially during the final step of migration. Therefore, in Sox5-deficient mice, the deep cortical layers exhibit a laminar inversion similar to the Reeler phenotype (Rice and Curran, 2001). Unlike Reeler and related mutants, however, lateborn upper-layer neurons in the Sox5-deficient neocortex migrate normally. This first example of a specific inversion of the deep layers indicates that the mechanisms enabling migration past earlier born neurons are not shared by projection neurons of all layers. How SOX5 mediates cell-type specific requirements in neuronal migration remains to be explored. This role is, however, likely to be unrelated to RELN expression, which is normal in Sox5deficient mice (Kwan et al., 2008; Lai et al., 2008), or to SOX5 regulation of $F e z f 2$ or $B c l 11 b$, because knockout mutants of these genes exhibit no defects in neuronal migration (Arlotta et al., 2005; Chen et al., 2005a; Molyneaux et al., 2005). SOX5 might control migration programs specific to deep-layer neurons or those that are common to all projection neurons but transcriptionally driven by distinct pathways in upper-layer neurons. Furthermore, whether early-born neurons non-cell-autonomously affect the migration of late-born neurons remains an open question. The early-born neuron-specific migration defects in Sox5-deficient mice suggest that neither an intact SP nor properly arranged deep layers are required for the correct positioning and formation of the upper cortical layers.

Another transcription factor that co-regulates multiple aspects of early-born neuron development is T-box brain factor 1 (TBR1). Analyses of mice lacking Tbrl revealed that Tbrl is required for a number of cortical developmental processes, including laminar positioning, molecular differentiation and axonal pathfinding (Hevner et al., 2001; Han et al., 2011; McKenna et al., 2011). TBR1 is selectively expressed in corticothalamic projection neurons positioned in L6 and in the SP, and in Cajal-Retzius neurons of the MZ (Fig. 4C), starting from E12.5 (Hevner et al., 2001). TBR1 is absent from $\mathrm{VZ}$ and SVZ progenitor cells, suggesting that, similar to SOX5, it functions in post-mitotic neurons that have reached the CP. 
The layer specificity of TBR1 expression decreases during the first postnatal week, when some upper-layer neurons begin to express TBR1 as well (Hevner et al., 2001; Bedogni et al., 2010; Han et al., 2011; McKenna et al., 2011). Tbrl controls the layer-specific pattern of molecular identity by suppressing the expression of Fezf2 and $B c l 11 b$ in L6 corticothalamic neurons (Han et al., 2011; McKenna et al., 2011). As a result of ectopic upregulation of Fezf, L6 neurons of the Tbrl-deficient neocortex aberrantly project axons into the corticospinal tract. In addition, Tbrl is required for the normal formation of the corticothalamic tract from L6 and SP neurons (Hevner et al., 2001; Han et al., 2011; McKenna et al., 2011). TBR1 further regulates the regional identity of the neocortex (Bedogni et al., 2010); in Tbr1-deficient mice, caudal cortex marker genes exhibit expanded domains and increased expression levels at the expense of those marking the rostral cortex.

Concurrent with the emergence of molecular identity and axonal connectivity of deep-layer neurons, TBR1 also regulates neuronal migration and the proper formation of the six-layered neocortex (Hevner et al., 2001; Han et al., 2011; McKenna et al., 2011). The migration defects in Tbrl-deficient mice, however, are complex and exhibit crucial differences compared with the inverted cortex of the Reeler mutant (Fig. 3B,D). In particular, SP neurons form an ectopic band of cells in the middle of the $\mathrm{CP}$ that exhibits a rostral-caudal gradient, being more deeply positioned in the frontal cortex (Han et al., 2011). In the caudal cortex, it is positioned more superficially in the upper $\mathrm{CP}$, where ectopic clusters of deep-layer neurons are present (Hevner et al., 2001; Han et al., 2011). These areal-dependent differences in migration phenotypes are consistent with a role for TBR1 in the regulation of regional identity (Bedogni et al., 2010). Interestingly, in Tbr1-deficient mice, L5 neurons are more widely distributed throughout the $\mathrm{CP}$, whereas upper-layer neurons are distributed bimodally, with a majority below the ectopic band of SP neurons and a significant minority reaching their normal positions in L2 and L3 (Hevner et al., 2001; Han et al., 2011). As TBR1 protein is not significantly or widely expressed in upper-layer neurons during mouse embryonic development (Hevner et al., 2001; Han et al., 2011), these defects are likely to be non-cell autonomous. The migration phenotype of the Tbrl-deficient neocortex might be, at least partially, attributed to decreased Reln expression (Hevner et al., 2001). Consistent with the rostral-caudal differences in the location of the ectopic band of SP neurons and the presence of deep-layer neuronal clusters, Reln expression is more severely decreased in the caudal cortex of Tbrl-deficient mice (Bedogni et al., 2010). Notably, Reln mRNA levels in these mice, even in the caudal cortex, were not completely lost but exhibited a decrease of $\sim 50 \%$. However, it has been shown that a massive loss of cortical Cajal-Retzius neurons, and a presumed severe decrease in RELN signaling, induced by genetic ablation of Cajal-Retzius progenitors does not affect layer formation (Yoshida et al., 2006), suggesting that only a small amount of Reln is required for neuronal migration. In addition to the differences in the migration phenotypes of the Tbrl and Reeler mutants, these data suggest that additional, as yet unknown, mechanisms downstream of Tbrl mediate its layer-specific effects on neuronal migration.

\section{Genetic programs regulating late-born neurons}

Late-born cortical projection neurons are positioned in the upper layers and project axons within the cortex. Their arrival at the $\mathrm{CP}$ and their subsequent differentiation steps follow those of the earlier-born deep-layer neurons. Laminar positioning and identity of late-born neurons, however, are controlled by distinct transcription factors and transcriptional programs. Among them is special AT-rich sequence binding protein 2 (SATB2), which is a matrix-attachment region interacting transcription factor. Analysis of Satb2-deficient mice revealed that SATB2 controls multiple aspects of upper-layer neuron development (Alcamo et al., 2008; Britanova et al., 2008). It is highly enriched in post-mitotic corticocortical projection neurons of L2-L5 (Fig. 4D), starting at E13.5 in newly born neurons as they migrate out of the germinal zones and into the IZ (Alcamo et al., 2008; Britanova et al., 2008). SATB2 is a positive transcriptional regulator of a number of layerspecific markers of corticocortical projection neurons, including cut-like homeobox 2 (Cux2), cadherin 10 (Cdh10) and RARrelated orphan receptor beta (Rorb) (Alcamo et al., 2008). In Satb2deficient mice, the expression of the L5 subcortical projection marker $B c l 11 b$ is ectopically upregulated in the upper layers (Alcamo et al., 2008; Britanova et al., 2008). Consistent with these changes in molecular identity, corticocortical projection neurons in the absence of Satb2 misroute their axons to subcortical targets, leading to agenesis of the corpus callosum (Alcamo et al., 2008; Britanova et al., 2008). Recently, Satb2 has also been shown to control the dendritic arborization of upper layer neurons (Zhang et al., 2011), indicating a broader role during neocortical development.

The role of Satb2 in neuronal migration, similar to its role in the control of neuronal identity and projections, is layer dependent. In Satb2-deficient mice, early-born neurons migrate normally to the SP and deep cortical layers. A large proportion of late-born upperlayer neurons in the perinatal cortex, however, are stalled in the IZ (Fig. 3E), failing to enter the CP (Alcamo et al., 2008; Britanova et al., 2008). Surprisingly, this neuronal migration defect is corrected within the first postnatal week, as most late-born neurons lacking Satb2 eventually reach their normal positions in the upper layers (Britanova et al., 2008; Zhang et al., 2011), indicating that the migration of upper layer neurons is not altogether defective, but is delayed in the absence of Satb2. The mechanisms that regulate the timing of the arrival of neurons to their proper CP location are unknown. It is possible that Satb2 controls layer-dependent programs that regulate the speed of neuronal migration. The possibility of upper layer-specific control of migration speed is consistent with the greater distance that these neurons must traverse, compared with their earlier-born counterparts, to reach their correct CP destination.

Upper-layer neuronal migration and identity are also regulated by POU3F2 (formerly BRN-2) and POU3F3 (formerly BRN-1), two related POU domain transcription factors that play overlapping roles during development of the neocortical layers (McEvilly et al., 2002; Sugitani et al., 2002). Pou3f2 and Pou3f3 are expressed in the projection neurons of L2-L5 (Fig. 4E,F), starting at E14.5 in the progenitor cells that give rise to these neurons and persisting throughout migration and post-migratory differentiation (McEvilly et al., 2002; Sugitani et al., 2002). The double-deletion of Pou3f2 and Pou $3 f 3$ reduces the expression of some upper layer-specific markers, including RAR-related orphan receptor beta (Rorb) and sortilin-related receptor, LDLR class A repeats-containing (Sorl1, formerly $m \operatorname{Sor} L A$ ) (Sugitani et al., 2002). The expression of molecular markers for L6 and SP neurons, however, is normal (McEvilly et al., 2002; Sugitani et al., 2002), indicating that Pou $3 f 2 / 3$ affects layer-dependent molecular identity, probably in a cell-autonomous manner. The role of Pou $3 f 2 / 3$ in the positioning of neurons is also neuronal subtype dependent. In Pou $3 f 2 / 3$ double knockout mice, the SP is properly segregated from the MZ during PP splitting and the relative positioning of L6 and SP neurons is normal (Fig. 3F). The double deletion of Pou $3 f 2 / 3$, however, reduces $\mathrm{VZ}$ and $\mathrm{SVZ}$ proliferation starting from E14.5, thus 
selectively affecting the generation of late-born neurons. The remaining neurons that are generated, although fewer in number, are able to migrate out of the germinal zones and express some markers of differentiated neurons (McEvilly et al., 2002; Sugitani et al., 2002). Their further migration, however, is defective, as they fail to surpass SP and L6 neurons during migration and cluster ectopically below the SP, which is thus displaced to a more superficial position (McEvilly et al., 2002; Sugitani et al., 2002).

The selective effects of Pou $3 f 2$ and Pou $3 f 3$ on the migration of the L2-L5 neurons in which they are expressed suggest that they function cell autonomously. Two mechanisms have been proposed to function downstream of Pou $3 f 2 / 3$ in regulating neuronal migration, one involving IL12A (p35) and CDK5R2 (p39), which are activators of cyclin-dependent kinase 5 (Cdk5) (McEvilly et al., 2002), and another mechanism involving disabled homolog 1 (DAB1), a cytoplasmic effector of Reln signaling (Sugitani et al., 2002). The precise contribution of these respective pathways to the Pou $3 f 2 / 3$ phenotype remains to be fully explored. The layerdependent migration phenotype of Pou $3 f 2 / 3$ double knockout mice closely resembles that observed following disrupted CDK5 signaling (Gilmore et al., 1998; Ko et al., 2001), and POU3F2 has been shown to directly bind the promoter regions of $1112 a$ and Cdk5r2 (McEvilly et al., 2002). However, the differences between the Pou $3 f 2 / 3$ double knockout defects and the complete laminar inversion of Reln or Dabl signaling mutants (Rice and Curran, 2001) might be explained by the age-dependent loss of $D a b 1$ expression in Pou $3 f 2 / 3$ mutants; Dabl is only severely reduced from E15.5 onwards in these mutants (Sugitani et al., 2002), which is consistent with the observed normal migration of early-born neurons and suggests that these neurons utilize alternative, nonPou $3 f 2 / 3$ mechanisms to drive the expression of Dabl. Therefore, Pou $3 f 2 / 3$ provides an example of layer-specific transcriptional control of a general migration mechanism, the disruption of which leads to lamina-dependent migration defects.

\section{Layer-dependent transcriptional programs regulating interneurons}

The proper positioning of cortical interneurons, which are generated in the ventral telencephalon, requires two modes of neuronal migration: tangential migration, by which interneurons reach the dorsal telencephalon, and radial migration, by which interneurons populate each layer of the neocortex. The laminar distribution of distinct subtypes of interneurons has been shown to depend on both their place of origin and their birthdate (Miyoshi and Fishell, 2011). Interestingly, layer acquisition by cortical interneurons is largely independent of RELN signaling (Pla et al., 2006) and might rely on established laminar differences in the radially derived projection neurons. Consistent with this possibility, a recent study has shown that the layer-specific expression of Fezf2 indirectly controls acquisition of specific subpopulations of cortical interneurons within that layer (Lodato et al., 2011). Fezf2 encodes a zinc-finger transcription factor that regulates the molecular and projection identity of deep-layer subcortical projection neurons (Chen et al., 2005a; Chen et al., 2005b; Molyneaux et al., 2005). Highly enriched in L5, it is required for the formation of subcortical axon tracts, including the corticospinal tract (Chen et al., 2005a; Chen et al., 2005b; Molyneaux et al., 2005), and its misexpression in upper-layer neurons induces ectopic subcortical projections (Chen et al., 2005b). Fezf2 is known not to be required for the migration of projection neurons; the arrangement and positioning of layers are normal in the Fezf2-deficient neocortex (Chen et al., 2005a; Molyneaux et al., 2005) and neuronal migration is unaffected when FEZF2 is selectively knocked down in projection neurons (Chen et al., 2005b). The overexpression of $F e z f 2$ in deep-layer neurons, most of which endogenously express Fezf2, was shown to arrest the migration of neurons in the IZ (Molyneaux et al., 2005), although this phenotype was not observed when Fezf2 was mis-expressed in upper-layer neurons using a weaker promoter (Chen et al., 2005b). A recent report describes evidence to suggest that $F e z f 2$ is required for the lamination of interneurons (Lodato et al., 2011). In the Fezf2deficient cortex, the number of somatostatin- and parvalbuminexpressing interneurons is significantly and specifically reduced in L5, indicating that loss of Fezf2-dependent L5 identity alters the distribution of subclasses of interneurons. Strikingly, these interneurons are recruited, in a neuronal subtype-dependent manner, to periventricular ectopic aggregates induced by Fezf2 overexpression or amyloid precursor protein knockdown (Lodato et al., 2011). This work represents the first report that regulation of the layer-specific pattern of projection neuron molecular identity affects the laminar distribution of interneurons and, hence, the organization and integration of excitatory and inhibitor neurons into functional neural circuits.

\section{Clinical relevance}

Defects in neuronal migration can lead to severe brain malformations in humans (Liu et al., 2008; Manzini and Walsh, 2011). In addition to gross abnormalities, alterations in the radial migration of projection neurons can more subtly affect the columnar organization of the neocortex (Rakic, 1988; Mountcastle, 1997; Kwan et al., 2012). Defective arrangement of cortical minicolumns, which have been hypothesized to form the basic unit of functional cortical circuitry, has been described in autistic and schizophrenic brains (Casanova et al., 2003). Other alterations in neuronal migration have also been associated with developmental psychiatric disorders (Geschwind and Levitt, 2007). One recent study found evidence of migration defects present in a significant proportion of autistic brains (Wegiel et al., 2010). Furthermore, the loss of contactin associated protein-like 2 (CNTNAP2, formerly CASPR2), which has been implicated in autism spectrum disorders (ASD), leads to migration defects in both mice and humans (Strauss et al., 2006; Peñagarikano et al., 2011). Although not definitive, neuronal migration defects have also been associated with schizophrenia (Akbarian et al., 1996; Anderson et al., 1996; Eastwood and Harrison, 2005; Yang et al., 2011). Furthermore, disrupted in schizophrenia 1 (DISC1), genetic variations of which have been found to correlate with psychotic and bipolar spectrum disorders and underlying cognitive impairments (Millar et al., 2000; Palo et al., 2007; Nicodemus et al., 2010), can modulate neuronal migration and connectivity in the neocortex (Kamiya et al., 2005; Kamiya et al., 2008; Jaaro-Peled et al., 2009; Kubo et al., 2010). Consistent with the notion that neuronal positioning and identity are mechanistically linked and that both are required for normal circuit formation, sequence and copy number variations in the genes encoding key transcription factors modulating positioning and identity (POU3F2, POU3F3, SATB2, SOX5 or FEZF2) have been found in patients with developmental and language delays, intellectual disability, schizophrenia or ASD (Bacchelli et al., 2003; Potkin et al., 2009; Rosenfeld et al., 2009; Rosenfeld et al., 2010; Cooper et al., 2011; Sanders et al., 2011; Lamb et al., 2012). These variations are likely to contribute to an increased burden for a spectrum of cognitive and motor neurodevelopmental disorders. Although TBR1 has not been genetically linked to a psychiatric disease, in mouse, Tbrl controls 
Table 1. Summary of potential contribution of layer-specific transcription factors to psychiatric and neurological disorders

\begin{tabular}{lll}
\hline Human gene & \multicolumn{1}{c}{ Finding } & Reference \\
\hline POU3F2 & Intergenic SNP linked to schizophrenia in GWAS & (Potkin et al., 2009) \\
POU3F3 & Falls within interval of de novo deletion CNV in 2q12.1-q13 in ASD & (Sanders et al., 2011) \\
SATB2 & Microdeletion in syndrome with mental retardation, hyperactivity, and aggression & (Rosenfeld et al., 2009) \\
& Disrupted by balanced translocation in case of ASD with dyspraxia & (Marshall et al., 2008) \\
SOX5 & Deletions have been associated with intellectual disability and language delay & (Lamb et al., 2012) \\
& A deletion CNV has been linked to ASD & (Rosenfeld et al., 2010) \\
TBR1 & Increased expression in the prefrontal cortex of bipolar patient brain & (Molnar et al., 2003) \\
& Regulates the expression of autism susceptibility gene AUTS2 & (Bedogni et al., 2010) \\
FEZF2 & SNP in conserved proximal 5' region associated with ASD in GWAS & (Wang et al., 2009) \\
\hline
\end{tabular}

ASD, autism spectrum disorder; CNV, copy number variation; GWAS, genome-wide association study; SNP, single nucleotide polymorphism.

the neocortical expression of Auts2, an ortholog of a human autism susceptibility gene (Bedogni et al., 2010). Thus, alterations in the transcription factors that concomitantly regulate the laminar position and neuronal identity of cortical neurons have been associated with a broad spectrum of psychiatric disorders (summarized in Table 1).

\section{Conclusions}

The assembly of neocortical layers and neuronal circuits requires exquisite regulation of many developmental processes. The functional segregation of neocortical circuitry into horizontal layers probably facilitates the integration and processing of inputs and the generation of appropriate outputs. Importantly, alterations to this laminar organization can contribute to psychiatric and neurological disorders. Here, we discussed how the two critical processes of layer formation, the migration of young neurons into the correct laminar positions within the emerging neocortex and the acquisition of layerspecific identity and connectivity, are concomitantly regulated by shared transcriptional mechanisms. Nearly every aspect of neocortical development has been shown to be under some form of transcriptional regulation (Monuki and Walsh, 2001; Hevner et al., 2006; Mallamaci and Stoykova, 2006; Guillemot, 2007; Hébert and Fishell, 2008; O'Leary and Sahara, 2008). Interestingly, coregulation of multiple cortical developmental processes by the same transcription programs is not limited to neuronal migration and layer specification. For example, the basic helix-loop-helix (bHLH) transcription factor neurogenin 2 (NEUROG2, formerly known as NGN2) controls not only the genesis of projection neurons (Guillemot, 2007), but also their migration via regulation of Rho GTPase 2 (Rnd2) (Heng et al., 2010; Pacary et al., 2011). The control of neuronal migration and morphology via regulation of Rnd2 also requires nuclear receptor subfamily 2, group F, member 1 ( $N r 2 f 1$, formerly Coup-tf1) (Alfano et al., 2011), which is critical to neocortical arealization (O'Leary and Sahara, 2008). Furthermore, paired box 6 (PAX6) and nuclear receptor subfamily 2, group E, member 1 (NR2E1, formerly TLX) cooperate to regulate both the regionalization of the neocortex and the generation of upper-layer neurons by specifying SVZ progenitors (Tarabykin et al., 2001; Land and Monaghan, 2003; Schuurmans et al., 2004). Therefore, pleiotropism appears to be a shared property of transcriptional regulation in neocortical development.

Another emerging theme of transcriptional control of lamination is that layer-specific programs may regulate shared, seemingly lamina-independent aspects of neuronal differentiation, such as dendrite and spine development. For example, the apical dendrites of both upper and deep layer neurons exhibit arborization near the $\mathrm{MZ}$ and are decorated by spines. In upper layer neurons, however, the upper layer-specific cut-like homeobox proteins CUX1 and CUX2 (Cubelos et al., 2010) regulate spine morphology and synaptogenesis, whereas SATB2 controls dendritic arborization (Zhang et al., 2011). The absence of these factors from the deep layers suggests that dendrite development and spine formation in deep-layer neurons are controlled by distinct, CUX- and SATB2independent mechanisms, further supporting the notion that shared developmental processes might be transcriptionally driven in a layer-dependent manner.

In addition to the transcriptional programs discussed here, posttranscriptional mechanisms also fine tune the precise spatiotemporal patterns of protein expression required for normal neocortical development. One example of such a posttranscriptional regulator is neuro-oncological ventral antigen 2 (NOVA2), which is an RNA-binding protein that modulates neuronal migration by regulating the alternative splicing of Dab1 (Yano et al., 2010). Recently, we have shown that another RNAbinding protein, the fragile X mental retardation protein (FMR1, also known as FMRP), post-transcriptionally regulates the layerand area-specific protein expression of neuronal nitric oxide synthase 1 (NOS1) in the mid-fetal human neocortex (Kwan et al., 2012). Therefore, the intricate regulation of neocortical developmental processes requires a combination of transcriptional and post-transcriptional mechanisms.

As disruptions to either neuronal migration or layer specification can lead to defective lamination, their co-regulation by the same molecules, especially transcription factors, might be advantageous. Transcription factors can affect the global gene expression of a cell by orchestrating, directly or indirectly, the activation and repression of different subsets of genes, thereby simultaneously mediating multiple cellular processes. Future experiments should be aimed at the identification and functional characterization of the downstream targets of these transcription factors, which will help to dissect the commonly regulated pathways mediating neuronal migration and identity acquisition. These downstream effectors are likely to be diverse in identity and function, as they contribute to a wide range of cellular and molecular processes. There might, however, be some common themes. For example, both neuronal migration and axon guidance require modulation of cytoskeletal dynamics, perhaps in response to certain external cues. Whether these downstream pathways may also be shared or used in a contextdependent manner between multiple processes remains to be explored. Together, the evidence presented in this review suggests that transcriptional co-regulation of distinct developmental processes, such as neuronal migration and identity specification, contributes significantly to neocortical organization and the establishment of functional neuronal circuits. Further evidence that this mode of regulation might play a major role in the development of human neocortical circuits is likely to come from additional characterization of potential changes in lamination and connectivity in human neurodevelopmental disorders. 


\section{Acknowledgements}

We apologize to all colleagues whose important work was not cited because of the large scope of this review and space limitations.

\section{Funding}

This article is supported by grants from the March of Dimes and James $\mathrm{S}$. McDonnell Foundation [N.S.] and the National Institutes of Health [N.S. and E.A.]. Deposited in PMC for release after 12 months.

\section{Competing interests statement}

The authors declare no competing financial interests.

\section{References}

Akbarian, S., Kim, J. J., Potkin, S. G., Hetrick, W. P., Bunney, W. E. and Jones, E. G. (1996). Maldistribution of interstitial neurons in prefrontal white matter of the brains of schizophrenic patients. Arch. Gen. Psychiatry 53, 425-436.

Alcamo, E. A., Chirivella, L, Dautzenberg, M, Dobreva, G, Fariñas, I, Grosschedl, R. and McConnell, S. K. (2008). Satb2 regulates callosal projection neuron identity in the developing cerebral cortex. Neuron 57, 364 377

Alfano, C., Viola, L., Heng, J. I., Pirozzi, M., Clarkson, M., Flore, G., De Maio, A., Schedl, A., Guillemot, F. and Studer, M. (2011). COUP-TFI promotes radial migration and proper morphology of callosal projection neurons by repressing Rnd2 expression. Development 138, 4685-4697.

Allendoerfer, K. L. and Shatz, C. J. (1994). The subplate, a transient neocortical structure: its role in the development of connections between thalamus and cortex. Annu. Rev. Neurosci. 17, 185-218.

Anderson, S. A., Volk, D. W. and Lewis, D. A. (1996). Increased density of microtubule associated protein 2 -immunoreactive neurons in the prefrontal white matter of schizophrenic subjects. Schizophr. Res. 19, 111-119.

Anderson, S. A., Eisenstat, D. D., Shi, L. and Rubenstein, J. L. (1997) Interneuron migration from basal forebrain to neocortex: dependence on Dlx genes. Science $\mathbf{2 7 8}, \mathbf{4 7 4 - 4 7 6}$

Ang, E. S., Haydar, T. F., Gluncic, V. and Rakic, P. (2003). Four-dimensional migratory coordinates of GABAergic interneurons in the developing mouse cortex. J. Neurosci. 23, 5805-5815.

Angevine, J. B., Jr and Sidman, R. L. (1961). Autoradiographic study of cell migration during histogenesis of cerebral cortex in the mouse. Nature 192, 766768

Anton, E. S., Kreidberg, J. A. and Rakic, P. (1999). Distinct functions of alpha3 and alpha(v) integrin receptors in neuronal migration and laminar organization of the cerebral cortex. Neuron 22, 277-289.

Arlotta, P., Molyneaux, B. J., Chen, J., Inoue, J., Kominami, R. and Macklis, J. D. (2005). Neuronal subtype-specific genes that control corticospinal motor neuron development in vivo. Neuron 45, 207-221.

Bacchelli, E., Blasi, F., Biondolillo, M., Lamb, J. A., Bonora, E., Barnby, G., Parr, J., Beyer, K. S., Klauck, S. M., Poustka, A. et al. (2003). Screening of nine candidate genes for autism on chromosome $2 q$ reveals rare nonsynonymous variants in the CAMP-GEFIl gene. Mol. Psychiatry 8, 916-924.

Bai, J., Ramos, R. L., Ackman, J. B., Thomas, A. M., Lee, R. V. and LoTurco, J. J. (2003). RNAi reveals doublecortin is required for radial migration in rat neocortex. Nat. Neurosci. 6, 1277-1283.

Batista-Brito, R. and Fishell, G. (2009). The developmental integration of cortical interneurons into a functional network. Curr. Top. Dev. Biol. 87, 81-118.

Bedogni, F., Hodge, R. D., Elsen, G. E., Nelson, B. R., Daza, R. A., Beyer, R. P., Bammler, T. K., Rubenstein, J. L. and Hevner, R. F. (2010). Tbr1 regulates regional and laminar identity of postmitotic neurons in developing neocortex. Proc. Natl. Acad. Sci. USA 107, 13129-13134.

Bortone, D. and Polleux, F. (2009). KCC2 expression promotes the termination of cortical interneuron migration in a voltage-sensitive calcium-dependent manner. Neuron 62, 53-71.

Britanova, O., de Juan Romero, C., Cheung, A., Kwan, K. Y., Schwark, M. Gyorgy, A., Vogel, T., Akopov, S., Mitkovski, M., Agoston, D. et al. (2008). Satb2 is a postmitotic determinant for upper-layer neuron specification in the neocortex. Neuron 57, 378-392.

Butt, S. J., Sousa, V. H., Fuccillo, M. V., Hjerling-Leffler, J., Miyoshi, G., Kimura, S. and Fishell, G. (2008). The requirement of Nkx2-1 in the temporal specification of cortical interneuron subtypes. Neuron $\mathbf{5 9}, 722-732$

Casanova, M. F., Buxhoeveden, D. and Gomez, J. (2003). Disruption in the inhibitory architecture of the cell minicolumn: implications for autism. Neuroscientist 9, 496-507.

Caviness, V. S., Jr (1982). Neocortical histogenesis in normal and reeler mice: a developmental study based upon [3H]thymidine autoradiography. Brain Res. 256, 293-302

Chen, B., Schaevitz, L. R. and McConnell, S. K. (2005a). Fezl regulates the differentiation and axon targeting of layer 5 subcortical projection neurons in cerebral cortex. Proc. Natl. Acad. Sci. USA 102, 17184-17189.

Chen, J. G., Rasin, M. R., Kwan, K. Y. and Sestan, N. (2005b). Zfp312 is required for subcortical axonal projections and dendritic morphology of deep- layer pyramidal neurons of the cerebral cortex. Proc. Natl. Acad. Sci. USA 102, 17792-17797

Cobos, I., Borello, U. and Rubenstein, J. L. (2007). Dlx transcription factors promote migration through repression of axon and dendrite growth. Neuron 54, 873-888.

Cooper, G. M., Coe, B. P., Girirajan, S., Rosenfeld, J. A., Vu, T. H., Baker, C., Williams, C., Stalker, H., Hamid, R., Hannig, V. et al. (2011). A copy number variation morbidity map of developmental delay. Nat. Genet. 43, 838-846.

Cubelos, B., Sebastián-Serrano, A., Beccari, L., Calcagnotto, M. E., Cisneros, E., Kim, S., Dopazo, A., Alvarez-Dolado, M., Redondo, J. M., Bovolenta, P. et al. (2010). Cux1 and Cux2 regulate dendritic branching, spine morphology, and synapses of the upper layer neurons of the cortex. Neuron 66, 523-535.

D'Arcangelo, G. and Curran, T. (1998). Reeler: new tales on an old mutant mouse. BioEssays 20, 235-244.

De Carlos, J. A. and O'Leary, D. D. (1992). Growth and targeting of subplate axons and establishment of major cortical pathways. J. Neurosci. 12, 1194 1211

DeFelipe, J. and Farinas, I. (1992). The pyramidal neuron of the cerebral cortex: morphological and chemical characteristics of the synaptic inputs. Prog. Neurobiol. 39, 563-607.

Du, T., Xu, Q., Ocbina, P. J. and Anderson, S. A. (2008). NKX2.1 specifies cortical interneuron fate by activating Lhx6. Development 135, 1559-1567.

Eastwood, S. L. and Harrison, P. J. (2005). Interstitial white matter neuron density in the dorsolateral prefrontal cortex and parahippocampal gyrus in schizophrenia. Schizophr. Res. 79, 181-188.

Fertuzinhos, S., Krsnik, Z., Kawasawa, Y. I., Rasin, M. R., Kwan, K. Y., Chen, J. G., Judas, M., Hayashi, M. and Sestan, N. (2009). Selective depletion of molecularly defined cortical interneurons in human holoprosencephaly with severe striatal hypoplasia. Cereb. Cortex 19, 2196-2207.

Frantz, G. D. and McConnell, S. K. (1996). Restriction of late cerebral cortical progenitors to an upper-layer fate. Neuron 17, 55-61.

Ge, W., He, F., Kim, K. J., Blanchi, B., Coskun, V., Nguyen, L., Wu, X., Zhao, J., Heng, J. I., Martinowich, K. et al. (2006). Coupling of cell migration with neurogenesis by proneural bHLH factors. Proc. Natl. Acad. Sci. USA 103, 13191324

Geschwind, D. H. and Levitt, P. (2007). Autism spectrum disorders: developmental disconnection syndromes. Curr. Opin. Neurobiol. 17, 103-111.

Gilmore, E. C., Ohshima, T., Goffinet, A. M., Kulkarni, A. B. and Herrup, K. (1998). Cyclin-dependent kinase 5-deficient mice demonstrate novel developmental arrest in cerebral cortex. J. Neurosci. 18, 6370-6377.

Gongidi, V., Ring, C., Moody, M., Brekken, R., Sage, E. H., Rakic, P. and Anton, E. S. (2004). SPARC-like 1 regulates the terminal phase of radial gliaguided migration in the cerebral cortex. Neuron 41, 57-69.

Guillemot, F. (2007). Cell fate specification in the mammalian telencephalon. Prog. Neurobiol. 83, 37-52.

Han, W., Kwan, K. Y., Shim, S., Lam, M. M., Shin, Y., Xu, X., Zhu, Y., Li, M. and Sestan, N. (2011). TBR1 directly represses Fezf2 to control the laminar origin and development of the corticospinal tract. Proc. Natl. Acad. Sci. USA 108, 3041-3046.

Hand, R., Bortone, D., Mattar, P., Nguyen, L., Heng, J. I., Guerrier, S., Boutt, E., Peters, E., Barnes, A. P., Parras, C. et al. (2005). Phosphorylation of Neurogenin2 specifies the migration properties and the dendritic morphology of pyramidal neurons in the neocortex. Neuron 48, 45-62.

Hébert, J. M. and Fishell, G. (2008). The genetics of early telencephalon patterning: some assembly required. Nat. Rev. Neurosci. 9, 678-685.

Heiman, M., Schaefer, A., Gong, S., Peterson, J. D., Day, M., Ramsey, K. E., Suárez-Fariñas, M., Schwarz, C., Stephan, D. A., Surmeier, D. J. et al. (2008). A translational profiling approach for the molecular characterization of CNS cell types. Cell 135, 738-748.

Heng, J. I., Chariot, A. and Nguyen, L. (2010). Molecular layers underlying cytoskeletal remodelling during cortical development. Trends Neurosci. 33, 3847.

Herrmann, K., Antonini, A. and Shatz, C. J. (1994). Ultrastructural evidence for synaptic interactions between thalamocortical axons and subplate neurons. Eur J. Neurosci. 6 , 1729-1742.

Hevner, R. F., Shi, L., Justice, N., Hsueh, Y., Sheng, M., Smiga, S., Bulfone, A., Goffinet, A. M., Campagnoni, A. T. and Rubenstein, J. L. (2001). Tbr1 regulates differentiation of the preplate and layer 6 . Neuron 29, 353-366.

Hevner, R. F., Hodge, R. D., Daza, R. A. and Englund, C. (2006). Transcription factors in glutamatergic neurogenesis: conserved programs in neocortex, cerebellum, and adult hippocampus. Neurosci. Res. 55, 223-233.

Jaaro-Peled, H., Hayashi-Takagi, A., Seshadri, S., Kamiya, A., Brandon, N. J. and Sawa, A. (2009). Neurodevelopmental mechanisms of schizophrenia: understanding disturbed postnatal brain maturation through neuregulin-1ErbB4 and DISC1. Trends Neurosci. 32, 485-495.

Jones, E. G. (1986). Neurotransmitters in the cerebral cortex. J. Neurosurg. 65 135-153.

Joshi, P. S., Molyneaux, B. J., Feng, L., Xie, X., Macklis, J. D. and Gan, L. (2008). Bhlhb5 regulates the postmitotic acquisition of area identities in layers II$\checkmark$ of the developing neocortex. Neuron 60, 258-272. 
Kamiya, A., Kubo, K., Tomoda, T., Takaki, M., Youn, R., Ozeki, Y., Sawamura, N., Park, U., Kudo, C., Okawa, M. et al. (2005). A schizophrenia-associated mutation of DISC1 perturbs cerebral cortex development. Nat. Cell. Biol. 7, 1167-1178.

Kamiya, A., Tan, P. L., Kubo, K., Engelhard, C., Ishizuka, K., Kubo, A., Tsukita, S., Pulver, A. E., Nakajima, K., Cascella, N. G. et al. (2008). Recruitment of PCM1 to the centrosome by the cooperative action of DISC1 and BBS4: candidate for psychiatric illnesses. Arch. Gen. Psychiatry 65, 996-1006.

Kawauchi, T. and Hoshino, M. (2008). Molecular pathways regulating cytoskeletal organization and morphological changes in migrating neurons. Dev. Neurosci. 30, 36-46.

Kawauchi, T., Sekine, K., Shikanai, M., Chihama, K., Tomita, K., Kubo, K., Nakajima, K., Nabeshima, Y. and Hoshino, M. (2010). Rab GTPasesdependent endocytic pathways regulate neuronal migration and maturation through $\mathrm{N}$-cadherin trafficking. Neuron 67, 588-602.

Ko, J., Humbert, S., Bronson, R. T., Takahashi, S., Kulkarni, A. B., Li, E. and Tsai, L. H. (2001). p35 and p39 are essential for cyclin-dependent kinase 5 function during neurodevelopment. J. Neurosci. 21, 6758-6771.

Kostovic, I. and Rakic, P. (1980). Cytology and time of origin of interstitial neurons in the white matter in infant and adult human and monkey telencephalon. J. Neurocytol. 9, 219-242.

Kostovic, I. and Rakic, P. (1990). Developmental history of the transient subplate zone in the visual and somatosensory cortex of the macaque monkey and human brain. J. Comp. Neurol. 297, 441-470.

Kriegstein, A. R. and Noctor, S. C. (2004). Patterns of neuronal migration in the embryonic cortex. Trends Neurosci. 27, 392-399.

Kubo, K., Tomita, K., Uto, A., Kuroda, K., Seshadri, S., Cohen, J., Kaibuchi, K., Kamiya, A. and Nakajima, K. (2010). Migration defects by DISC1 knockdown in C57BL/6, 129X1/SvJ, and ICR strains via in utero gene transfer and virus-mediated RNAi. Biochem. Biophys. Res. Commun. 400, 631-637.

Kwan, K. Y., Lam, M. M., Krsnik, Z., Kawasawa, Y. I., Lefebvre, V. and Sestan, N. (2008). SOX5 postmitotically regulates migration, postmigratory differentiation, and projections of subplate and deep-layer neocortical neurons. Proc. Natl. Acad. Sci. USA 105, 16021-16026

Kwan, K. Y., Lam, M. M. S., Johnson, M. B., Dube, U., Shim, S., Rasin, M. R. Sousa, A. M. M., Fertuzinhos, S., Chen, J. G., Arellano, J. I. et al. (2012) Species-dependent post-transcriptional regulation of NOS1 by FMRP in the developing cerebral cortex. Cell (in press).

Lai, T., Jabaudon, D., Molyneaux, B. J., Azim, E., Arlotta, P., Menezes, J. R. and Macklis, J. D. (2008). SOX5 controls the sequential generation of distinct corticofugal neuron subtypes. Neuron 57, 232-247.

Lamb, A. N., Rosenfeld, J. A., Neill, N. J., Talkowski, M. E., Blumenthal, I., Girirajan, S., Keelean-Fuller, D., Fan, Z., Pouncey, J., Stevens, C. et al. (2012). Haploinsufficiency of SOX5 at 12 p12.1 is associated with developmental delays with prominent language delay, behavior problems, and mild dysmorphic features. Hum. Mutat. (in press).

Lambert de Rouvroit, C. and Goffinet, A. M. (1998). A new view of early cortical development. Biochem. Pharmacol. 56, 1403-1409.

Land, P. W. and Monaghan, A. P. (2003). Expression of the transcription factor, tailless, is required for formation of superficial cortical layers. Cereb. Cortex $\mathbf{1 3}$ 921-931

Leone, D. P., Srinivasan, K., Chen, B., Alcamo, E. and McConnell, S. K. (2008). The determination of projection neuron identity in the developing cerebral cortex. Curr. Opin. Neurobiol. 18, 28-35.

Letinic, K., Zoncu, R. and Rakic, P. (2002). Origin of GABAergic neurons in the human neocortex. Nature 417, 645-649.

Liu, H., Hu, Q., Kaufman, A., D’Ercole, A. J. and Ye, P. (2008). Developmental expression of histone deacetylase 11 in the murine brain. J. Neurosci. Res. 86, 537-543

Liu, J. S. (2011). Molecular genetics of neuronal migration disorders. Curr. Neurol. Neurosci. Rep. 11, 171-178.

Lodato, S., Rouaux, C., Quast, K. B., Jantrachotechatchawan, C., Studer, M. Hensch, T. K. and Arlotta, P. (2011). Excitatory projection neuron subtypes control the distribution of local inhibitory interneurons in the cerebral cortex. Neuron 69, 763-779.

LoTurco, J. J. and Bai, J. (2006). The multipolar stage and disruptions in neurona migration. Trends Neurosci. 29, 407-413.

Mallamaci, A. and Stoykova, A. (2006). Gene networks controlling early cerebral cortex arealization. Eur. J. Neurosci. 23, 847-856.

Manzini, M. C. and Walsh, C. A. (2011). What disorders of cortical development tell us about the cortex: one plus one does not always make two. Curr. Opin. Genet. Dev. 21, 333-339.

Marín, O. and Rubenstein, J. L. (2003). Cell migration in the forebrain. Annu. Rev. Neurosci. 26, 441-483.

Marin-Padilla, M. (1971). Early prenatal ontogenesis of the cerebral cortex (neocortex) of the cat (Felis domestica). A Golgi study. I. The primordial neocortical organization. Z Anat. Entwicklungsgesch 134, 117-145.

Marin-Padilla, M. (1978). Dual origin of the mammalian neocortex and evolution of the cortical plate. Anat. Embryol. (Berl.) 152, 109-126.
Markram, H., Toledo-Rodriguez, M., Wang, Y., Gupta, A., Silberberg, G. and Wu, C. (2004). Interneurons of the neocortical inhibitory system. Nat. Rev. Neurosci. 5, 793-807.

Marshall, C. R., Noor, A., Vincent, J. B., Lionel, A. C., Feuk, L., Skaug, J., Shago, M., Moessner, R., Pinto, D., Ren, Y. et al. (2008). Structural variation of chromosomes in autism spectrum disorder. Am. J. Hum. Genet. 82, 477-488.

McEvilly, R. J., de Diaz, M. O., Schonemann, M. D., Hooshmand, F. and Rosenfeld, M. G. (2002). Transcriptional regulation of cortical neuron migration by POU domain factors. Science 295, 1528-1532

McKenna, W. L., Betancourt, J., Larkin, K. A., Abrams, B., Guo, C., Rubenstein, J. L. and Chen, B. (2011). Tbr1 and Fezf2 regulate alternate corticofugal neuronal identities during neocortical development. J. Neurosci. 31, 549-564.

Millar, J. K., Wilson-Annan, J. C., Anderson, S., Christie, S., Taylor, M. S. Semple, C. A., Devon, R. S., St Clair, D. M., Muir, W. J., Blackwood, D. H. et al. (2000). Disruption of two novel genes by a translocation co-segregating with schizophrenia. Hum. Mol. Genet. 9, 1415-1423.

Miyoshi, G. and Fishell, G. (2011). GABAergic interneuron lineages selectively sort into specific cortical layers during early postnatal development. Cereb. Cortex 21, 845-852

Miyoshi, G., Butt, S. J., Takebayashi, H. and Fishell, G. (2007). Physiologically distinct temporal cohorts of cortical interneurons arise from telencephalic Olig2expressing precursors. J. Neurosci. 27, 7786-7798.

Miyoshi, G., Hjerling-Leffler, J., Karayannis, T., Sousa, V. H., Butt, S. J., Battiste, J., Johnson, J. E., Machold, R. P. and Fishell, G. (2010). Genetic fate mapping reveals that the caudal ganglionic eminence produces a large and diverse population of superficial cortical interneurons. J. Neurosci. 30,1582 1594

Molliver, M. E., Kostovic, I. and van der Loos, H. (1973). The development of synapses in cerebral cortex of the human fetus. Brain Res. 50, 403-407.

Molnar, M., Potkin, S. G., Bunney, W. E. and Jones, E. G. (2003). MRNA expression patterns and distribution of white matter neurons in dorsolateral prefrontal cortex of depressed patients differ from those in schizophrenia patients. Biol. Psychiatry 53, 39-47

Molyneaux, B. J., Arlotta, P., Hirata, T., Hibi, M. and Macklis, J. D. (2005). Fez is required for the birth and specification of corticospinal motor neurons. Neuron 47, 817-831.

Molyneaux, B. J., Arlotta, P., Menezes, J. R. and Macklis, J. D. (2007). Neuronal subtype specification in the cerebral cortex. Nat. Rev. Neurosci. 8, 427 437

Monuki, E. S. and Walsh, C. A. (2001). Mechanisms of cerebral cortical patterning in mice and humans. Nat. Neurosci. 4, 1199-1206.

Mountcastle, V. B. (1997). The columnar organization of the neocortex. Brain $120,701-722$

Nadarajah, B. and Parnavelas, J. G. (2002). Modes of neuronal migration in the developing cerebral cortex. Nat. Rev. Neurosci. 3, 423-432.

Nagano, T., Morikubo, S. and Sato, M. (2004). Filamin A and FILIP (Filamin AInteracting Protein) regulate cell polarity and motility in neocortical subventricular and intermediate zones during radial migration. J. Neurosci. 24 9648-9657

Nicodemus, K. K., Callicott, J. H., Higier, R. G., Luna, A., Nixon, D. C., Lipska, B. K., Vakkalanka, R., Giegling, I., Rujescu, D., St Clair, D. et al. (2010). Evidence of statistical epistasis between DISC1, CIT and NDEL1 impacting risk for schizophrenia: biological validation with functional neuroimaging. Hum. Genet. 127, 441-452.

Nóbrega-Pereira, S., Kessaris, N., Du, T., Kimura, S., Anderson, S. A. and Marín, 0. (2008). Postmitotic Nkx2-1 controls the migration of telencephalic interneurons by direct repression of guidance receptors. Neuron 59, 733-745.

Noctor, S. C., Martinez-Cerdeno, V., Ivic, L. and Kriegstein, A. R. (2004a). Cortical neurons arise in symmetric and asymmetric division zones and migrate through specific phases. Nat. Neurosci. 7, 136-144.

Noctor, S. C., Martínez-Cerdeño, V., Ivic, L. and Kriegstein, A. R. (2004b) Cortical neurons arise in symmetric and asymmetric division zones and migrate through specific phases. Nat. Neurosci. 7, 136-144.

O'Leary, D. D. and Koester, S. E. (1993). Development of projection neuron types, axon pathways, and patterned connections of the mammalian cortex. Neuron 10, 991-1006

O'Leary, D. D. and Sahara, S. (2008). Genetic regulation of arealization of the neocortex. Curr. Opin. Neurobiol. 18, 90-100.

Pacary, E., Heng, J., Azzarelli, R., Riou, P., Castro, D., Lebel-Potter, M., Parras, C., Bell, D. M., Ridley, A. J., Parsons, M. et al. (2011). Proneural transcription factors regulate different steps of cortical neuron migration through Rndmediated inhibition of RhoA signaling. Neuron 69, 1069-1084

Palo, O. M., Antila, M., Silander, K., Hennah, W., Kilpinen, H., Soronen, P., Tuulio-Henriksson, A., Kieseppä, T., Partonen, T., Lönnqvist, J. et al. (2007). Association of distinct allelic haplotypes of DISC 1 with psychotic and bipolar spectrum disorders and with underlying cognitive impairments. Hum. Mol. Genet. 16, 2517-2528.

Peñagarikano, O., Abrahams, B. S., Herman, E. I., Winden, K. D., Gdalyahu, A., Dong, H., Sonnenblick, L. I., Gruver, R., Almajano, J., Bragin, A. et al. 
(2011). Absence of CNTNAP2 leads to epilepsy, neuronal migration abnormalities, and core autism-related deficits. Cell 147, 235-246.

Pla, R., Borrell, V., Flames, N. and Marín, O. (2006). Layer acquisition by cortical GABAergic interneurons is independent of Reelin signaling. J. Neurosci. $\mathbf{2 6}$ 6924-6934.

Potkin, S. G., Turner, J. A., Guffanti, G., Lakatos, A., Fallon, J. H., Nguyen, D. D., Mathalon, D., Ford, J., Lauriello, J., Macciardi, F. et al. (2009). A genome-wide association study of schizophrenia using brain activation as a quantitative phenotype. Schizophr. Bull. 35, 96-108.

Rakic, P. (1974). Neurons in rhesus monkey visual cortex: systematic relation between time of origin and eventual disposition. Science 183, 425-427

Rakic, P. (1976). Prenatal genesis of connections subserving ocular dominance in the rhesus monkey. Nature 261, 467-471.

Rakic, P. (1988). Specification of cerebral cortical areas. Science 241, 170-176.

Rash, B. G. and Grove, E. A. (2006). Area and layer patterning in the developing cerebral cortex. Curr. Opin. Neurobiol. 16, 25-34.

Rice, D. S. and Curran, T. (2001). Role of the reelin signaling pathway in central nervous system development. Annu. Rev. Neurosci. 24, 1005-1039.

Rosenfeld, J. A., Ballif, B. C., Lucas, A., Spence, E. J., Powell, C., Aylsworth, A. S., Torchia, B. A. and Shaffer, L. G. (2009). Small deletions of SATB2 cause some of the clinical features of the 2 q33.1 microdeletion syndrome. PLOS ONE 4, e6568.

Rosenfeld, J. A., Ballif, B. C., Torchia, B. S., Sahoo, T., Ravnan, J. B., Schultz,

R., Lamb, A., Bejjani, B. A. and Shaffer, L. G. (2010). Copy number variations associated with autism spectrum disorders contribute to a spectrum of neurodevelopmental disorders. Genet. Med. 12, 694-702.

Rubenstein, J. L. (2011). Annual Research Review: Development of the cerebral cortex: implications for neurodevelopmental disorders. J. Child Psychol. Psychiatry 52, 339-355.

Sánchez-Alcañiz, J. A., Haege, S., Mueller, W., Pla, R., Mackay, F., Schulz, S., López-Bendito, G., Stumm, R. and Marín, O. (2011). Cxcr7 controls neuronal migration by regulating chemokine responsiveness. Neuron 69, 77-90.

Sanders, S. J., Ercan-Sencicek, A. G., Hus, V., Luo, R., Murtha, M. T., MorenoDe-Luca, D., Chu, S. H., Moreau, M. P., Gupta, A. R., Thomson, S. A. et al. (2011). Multiple recurrent de novo CNVs, including duplications of the 7q11.23 Williams syndrome region, are strongly associated with autism. Neuron 70, $863-$ 885.

Schuurmans, C., Armant, O., Nieto, M., Stenman, J. M., Britz, O., Klenin, N., Brown, C., Langevin, L. M., Seibt, J., Tang, H. et al. (2004). Sequential phases of cortical specification involve Neurogenin-dependent and -independent pathways. EMBO J. 23, 2892-2902

Sessa, A., Mao, C. A., Colasante, G., Nini, A., Klein, W. H. and Broccoli, V. (2010). Tbr2-positive intermediate (basal) neuronal progenitors safeguard cerebral cortex expansion by controlling amplification of pallial glutamatergic neurons and attraction of subpallial GABAergic interneurons. Genes Dev. 24 1816-1826.

Steindler, D. A. and Colwell, S. A. (1976). Reeler mutant mouse: maintenance of appropriate and reciprocal connections in the cerebral cortex and thalamus. Brain Res. 113, 386-393

Strauss, K. A., Puffenberger, E. G., Huentelman, M. J., Gottlieb, S., Dobrin, S. E., Parod, J. M., Stephan, D. A. and Morton, D. H. (2006). Recessive symptomatic focal epilepsy and mutant contactin-associated protein-like 2. N. Engl. J. Med. 354, 1370-1377.

Sugino, K., Hempel, C. M., Miller, M. N., Hattox, A. M., Shapiro, P., Wu, C., Huang, Z. J. and Nelson, S. B. (2006). Molecular taxonomy of major neuronal classes in the adult mouse forebrain. Nat. Neurosci. 9,99-107.

Sugitani, Y., Nakai, S., Minowa, O., Nishi, M., Jishage, K., Kawano, H., Mori, K., Ogawa, M. and Noda, T. (2002). Brn-1 and Brn-2 share crucial roles in the production and positioning of mouse neocortical neurons. Genes Dev. 16, 17601765.
Tabata, H. and Nakajima, K. (2003). Multipolar migration: the third mode of radial neuronal migration in the developing cerebral cortex. J. Neurosci. 23, 9996-10001

Tabata, H., Kanatani, S. and Nakajima, K. (2009). Differences of migratory behavior between direct progeny of apical progenitors and basal progenitors in the developing cerebral cortex. Cereb. Cortex 19, 2092-2105.

Tarabykin, V., Stoykova, A., Usman, N. and Gruss, P. (2001). Cortical upper layer neurons derive from the subventricular zone as indicated by Svet1 gene expression. Development 128, 1983-1993.

The Boulder Committee (1970). Embryonic vertebrate central nervous system revised terminology. The Boulder Committee. Anat. Rec. 166, 257-261.

Tissir, F. and Goffinet, A. M. (2003). Reelin and brain development. Nat. Rev. Neurosci. 4, 496-505.

Tsai, J. W., Chen, Y., Kriegstein, A. R. and Vallee, R. B. (2005). LIS1 RNA interference blocks neural stem cell division, morphogenesis, and motility at multiple stages. J. Cell Biol. 170, 935-945.

Valiente, M. and Marín, 0. (2010). Neuronal migration mechanisms in development and disease. Curr. Opin. Neurobiol. 20, 68-78.

Wang, K., Zhang, H., Ma, D., Bucan, M., Glessner, J. T., Abrahams, B. S., Salyakina, D., Imielinski, M., Bradfield, J. P., Sleiman, P. M. et al. (2009). Common genetic variants on $5 p 14.1$ associate with autism spectrum disorders. Nature 459, 528-533

Wang, Y., Li, G., Stanco, A., Long, J. E., Crawford, D., Potter, G. B., Pleasure, S. J., Behrens, T. and Rubenstein, J. L. (2011). CXCR4 and CXCR7 have distinct functions in regulating interneuron migration. Neuron 69, 61-76.

Wegiel, J., Kuchna, I., Nowicki, K., Imaki, H., Marchi, E., Ma, S. Y., Chauhan, A., Chauhan, V., Bobrowicz, T. W., de Leon, M. et al. (2010). The neuropathology of autism: defects of neurogenesis and neuronal migration, and dysplastic changes. Acta Neuropathol. 119, 755-770.

Westerlund, N., Zdrojewska, J., Padzik, A., Komulainen, E., Björkblom, B., Rannikko, E., Tararuk, T., Garcia-Frigola, C., Sandholm, J., Nguyen, L. et al. (2011). Phosphorylation of SCG10/stathmin-2 determines multipolar stage exit and neuronal migration rate. Nat. Neurosci. 14, 305-313.

Wonders, C. P. and Anderson, S. A. (2006). The origin and specification of cortical interneurons. Nat. Rev. Neurosci. 7, 687-696.

Xu, Q., Cobos, I., De La Cruz, E., Rubenstein, J. L. and Anderson, S. A. (2004) Origins of cortical interneuron subtypes. J. Neurosci. 24, 2612-2622.

Yang, Y., Fung, S. J., Rothwell, A., Tianmei, S. and Weickert, C. S. (2011). Increased interstitial white matter neuron density in the dorsolateral prefrontal cortex of people with schizophrenia. Biol. Psychiatry 69, 63-70.

Yano, M., Hayakawa-Yano, Y., Mele, A. and Darnell, R. B. (2010). Nova2 regulates neuronal migration through an RNA switch in disabled-1 signaling. Neuron 66, 848-858.

Yokota, Y., Gashghaei, H. T., Han, C., Watson, H., Campbell, K. J. and Anton, E. S. (2007a). Radial glial dependent and independent dynamics of interneuronal migration in the developing cerebral cortex. PLOS ONE 2, e794.

Yokota, Y., Ring, C., Cheung, R., Pevny, L. and Anton, E. S. (2007b). Nap1regulated neuronal cytoskeletal dynamics is essential for the final differentiation of neurons in cerebral cortex. Neuron 54, 429-445.

Yoshida, M., Assimacopoulos, S., Jones, K. R. and Grove, E. A. (2006). Massive loss of Cajal-Retzius cells does not disrupt neocortical layer order. Development 133, 537-545.

Yu, X. and Zecevic, N. (2011). Dorsal radial glial cells have the potential to generate cortical interneurons in human but not in mouse brain. J. Neurosci. 31, 2413-2420.

Zhang, L., Song, N. N., Chen, J. Y., Huang, Y., Li, H. and Ding, Y. Q. (2011). Satb2 is required for dendritic arborization and soma spacing in mouse cerebral cortex. Cereb. Cortex. (in press). 